\title{
Os Flintstones e o preconceito na escola
}

\section{The Flintstones and prejudice in school}

\author{
Tânia Maria Baibich*
}

\begin{abstract}
RESUMO
Em nosso país, que é tido pelo "imaginário mundial” e por si mesmo, como um paraíso de mestiçagem, a hipocrisia do não questionamento suficiente no que tange às diferenças que são muitas, tem permitido a manutenção e o agravamento do silêncio que fala a favor do preconceito. A não pluralidade na educação é apenas uma das formas de preservação do grande tapete da "democracia racial" que esconde a falta de democracia real.

Este artigo, ao passear por entre os conceitos de alteridade e preconceito, pretende convidar o leitor à reflexão sobre a prática da negação do preconceito no âmbito da escola e suas conseqüências funestas para a manutenção do mesmo no tecido social.

Com o intuito de ilustrar as considerações acerca do processo de "varredura para debaixo do tapete" utilizado na maioria dos espaços de socialização em nossa sociedade e não menos notadamente nas escolas, busca, mediante entrevista com alguns professores de uma escola pública do Estado do Paraná, dados para melhor diagnosticar a atitude da escola bem como a dos professores no que tange ao reconhecimento da existência à profilaxia e/ou o tratamento do preconceito.

As análises indicam que a escola, mesmo a que se pretende voltada à convivência entre os diferentes, enfrenta, além dos inimigos já conhecidos, a grande e aparentemente intransponível barreira da negação que, deliberadamente ou não, promove a manutenção do estado de preconceito bem como da geração de indivíduos preconceituosos.

Palavras-chaves: Preconceito, alteridade, escola.
\end{abstract}

* Professor Adjunto III, do Departamento de Teoria e Prática de Ensino, do Setor de Educação, da Universidade Federal do Paraná. tbaibich@zaz.com.br 


\begin{abstract}
In our country, that is seen by the "global imaginary" and by itself as a paradise of the crossing of races, the hypocrisy of the not enough questioning about the differences, that are a few, has allowed for the maintenance and the aggravating of the silence that speaks in favour of prejudice. The lack of plurality in education is only one of the forms of preservation of the big carpet of the "racial democracy" that hides the lack of real democracy.

This paper, while going through the concepts of alterity and prejudice, intends to invite the reader to reflect about the practice of the prejudice negation in the school space and its regrettable consequences to its maintenance in the social web.

Aiming at illustrating the considerations about the process of "sweeping to under the carpet" using most of the socialising spaces in our society and, not less notably, in the schools, searches, by means of some interviews with teachers of a Public School of Paraná State, data to allow for a better diagnostic of the school attitude, as well as of the teachers' in respect to the acknowledge of the existence, to the profilaxes and/or the treatment of the prejudice.

The analyses indicate that the school, even when it is intended to be orientated to the coexistence of the different, faces, apart from the enemies already known, the big and apparently non transposed barrier of the negation that, deliberately or not, promotes the maintenance of the state of prejudice as well as the generation of prejudiced individuals.
\end{abstract}

Key-words: Ethics, prejudice, education.

A celeuma sobre a verdadeira data de início do III milênio, se em janeiro de 2000 ou de 2001, que nos perseguiu durante no mínimo dois anos, parece ter se esgotado. O III milênio começou, efetivamente, em 11 de setembro último, com o desabamento das "Torres de Babel do século XX". O atentado terrorista que matou, sem deixar resquícios, bem mais do que os $3.900 \mathrm{mil}$ homens e mulheres de todos os níveis sociais, de todas as religiões, de todas as etnias que a nefasta contabilidade do desastre computou, matou, principalmente, toda e qualquer possibilidade da humanidade não mais pensar as conseqüências que a intolerância à diferença é capaz de produzir.

Nestes tempos em que, cada vez mais, os homens eram definidos como força de trabalho, poder de compra ou consumidores e desta feita, transfor- 
mados pela globalização (aqueles que não marginalizados do consumo) em "cidadãos do mesmo mundo" quase era possível viver a ilusão de que o comércio fosse nossa pátria. A derrubada do "Centro Mundial do Comércio," por parte daqueles que exaltam nossas diferenças como fés irredutíveis e inconciliáveis, que nos faz "iguais" como agentes econômicos, simboliza que esses escombros, para mais além de si, são os escombros de nossas políticas, ou da ausência delas, voltadas para a diversidade e para a Paz. ${ }^{1}$

Um dos valores tomados como "princípio" pela civilização ocidental pós-genocídio e do qual se fala muito, é o da aceitação das diferenças. Teoricamente, estamos todos de acordo; sabemos como agir de forma "politicamente correta" quando perante a possibilidade de crítica e, na intimidade, exercer todo nosso preconceito.

Em nosso país, que é tido pelo imaginário mundial e por si mesmo como um paraíso de mestiçagem, a hipocrisia do não questionamento suficiente no que tange às diferenças, que são muitas, tem permitido a manutenção e o agravamento do silêncio que fala em favor do preconceito. A não-pluralidade na educação é apenas uma das formas de preservação do grande tapete da "democracia racial" que esconde a falta de democracia real.

A síntese dos indicadores sociais da década de 90, divulgada em 4 de abril de 2001 pelo Instituto Brasileiro de Geografia e Estatística, coloca em perspectiva o status do país como uma das nações mais injustas do planeta. Par e passo com a manutenção do fosso que separa os mais ricos dos mais pobres (14\% da renda fica com os $50 \%$ mais pobres, enquanto $13,1 \%$ da renda fica com os $1 \%$ mais ricos), mantêm-se as desigualdades regionais, as relativas aos homens e mulheres e as entre brancos e negros (incluídos aí também os pardos).

No Brasil, país no qual apenas $5,4 \%$ da população afirma que é negra, enquanto $54 \%$ se declaram brancos e $39,9 \%$, pardos, ${ }^{2}$ segundo estes mesmos dados, o analfabetismo cresce com a pigmentação da pele: não sabem ler $8,3 \%$ dos brancos, $19,6 \%$ dos pardos e $21 \%$ dos negros. Negros e pardos representam $45 \%$ da população, mas são $64 \%$ dos pobres e $69 \%$ dos indigentes do país. Ao cruzar dados de educação e renda no país é possível comprovar, que dentre a população economicamente ativa, os negros têm, em relação aos

1 Tornar esta expressão maiúscula, parece, mais que nunca, o caminho que, como educadores, devemos indicar.

2 Em pesquisa realizada pelo IBGE em 1998, na qual os próprios entrevistados se atribuíam uma cor, apareceram 143 designações, como canela, sarará, cabo verde, marrom e chocolate. (Folha de São Paulo, 22 out. 2001). 
brancos, menos da metade de anos de estudo e ganham menos da metade do que os brancos ganham.

Apesar do grito das estatísticas, das pesquisas universitárias e das evidências cotidianas, o país considera-se livre de preconceitos e trata a situação como se a mesma não constituísse um problema. O que ocorre, notadamente, é uma atitude de ocultamento, de forma a encobrir a realidade. O uso da palavra "moreno" para referir-se a negros ou o fato de grande parte da população negra autodenominar-se "pardo" para fins de pesquisa populacional, são claros exemplos deste fenômeno tão contraditório de nossa incômoda relação com a existência do preconceito. ${ }^{3}$

A educação, condição privilegiada de transmissão da cultura, tem enfrentado de forma inócua os conflitos e os processos de dominação, quer sejam eles de cunho de diferenças de classe, quer sejam baseados em etnias, sexo, religião, regionalidade, ou em outros fatores. A escola, acreditando no mito da mestiçagem, funciona como estufa para o crescimento e a manutenção do processo de exclusão dos diferentes. ${ }^{4}$ É imperioso, disse-nos, aos berros, o horror do 11 de setembro, encontrar a caixa preta de nossa história de violência. É urgente que sejamos capazes de dissecá-la e, olhando de frente para ela, assumir a responsabilidade tanto por nossos pensamentos, quanto por nossos sentimentos e nossas ações, inclusive, e muito especialmente, aquelas tidas como "politicamente incorretas".

Esse artigo, ao passear por entre os conceitos de alteridade e preconceito, sustentado em análises preliminares de dados empíricos, pretende convidar o leitor à reflexão sobre a prática da negação do preconceito no âmbito da escola e suas conseqüências funestas para a manutenção do mesmo no tecido social.

3 Apesar do fato de que desde 1989 a discriminação racial passou a ser considerada crime, há hoje no Brasil menos de 150 processos por crime de racismo, segundo levantamento do Ministério das Relações Exteriores feito para a $3^{\text {a }}$. Conferência da ONU contra o racismo, realizada na África do Sul em setembro último.

4 Segundo Rosemberg (2001), a desigualdade entre raças no desempenho escolar é devida tanto a fatores socioeconômicos quanto ao que chama de "pessimismo racial", que significa descrença na possibilidade de sucesso do aluno de ascendência negra. Para a pesquisadora, "a criança negra é considerada, de antemão, o candidato mais provável à repetência por todo o aparato educacional - do professor ao diretor e ao secretário de Educação." (Folha de São Paulo, 22 out. 2001). 


\title{
Da alteridade $^{5}$
}

As diferenças culturais constituem a maior parte dos motivos da alteridade. Desde sempre os povos têm considerado a si mesmos como "o povo" e aos demais como "os outros": os gregos e os babaroi, os judeus e os goyim, os japoneses e os gaijin.

Pierre Clastres, antrópologo francês que conviveu muito tempo com tribos indígenas sul-americanas, menciona o fato de freqüentemente os membros dessas tribos designarem a si mesmos com um vocábulo que em sua língua era sinônimo de "os homens" e reservarem para seus congêneres de tribos vizinhas termos como "ovos de piolho", "subhomens" ou equivalentes com valor pejorativo. (VIÑAR, 1998, p. 173).

Para a formação e para a subsistência da unidade grupal, a necessidade do sentimento de "iniminização" em relação àqueles que estão fora do grupo constitui o arcabouço da estrutura do estrangeiro. É na afirmação da diferença que a identidade finca suas estacas mais primitivas, demarcando fronteiras de estrutura anímica.

\begin{abstract}
Ainda que historicamente sempre tenha havido estrangeiros, são as nações modernas que puseram em prática a segregação, termo que vem do latim e que quer dizer separar do rebanho. A partir do século XVI segregare passou a significar o ato pelo qual se separavam as populações brancas das de cor, ou seja, passou a significar o apartheid. Com a Segunda Guerra Mundial tornou-se um fenômeno de civilização, um sintoma social. Foi o totalitarismo moderno que mostrou até onde pode ir o humano quando se acirram as questões de diferenças, que mostrou que a segregação, que existe em toda sociedade, pode chegar - como aliás chegou - a negar a própria condição de humano ao outro, reduzindo-o a um simples número tatuado no braço [...] (KolTAI, 1998, p. 108)
\end{abstract}

O outro, o estrangeiro (do latim extraneous: vindo de fora), a partir do Império Romano passa a representar uma categoria política e a ser definido

5 Para maiores dados sobre alteridade vide BAIBICH, T. M. Fronteiras da identidade: $\mathrm{o}$ auto-ódio tropical. Curitiba: Moinho do Verbo, 2001. 
enquanto não-familiar praticamente em todos os idiomas. No sentido de reafirmar a identidade e a pertença a seu grupo são atribuídas ao outro (alter) características, também grupais, supergeneralizadas sobre seu comportamento ou constituição. Estas características são comumente negativas e, quando "positivas", carregam consigo uma avaliação negativa: não há muita diferença entre dizer que os judeus mostram uma forte solidariedade grupal e acusá-los de serem um grupo que funciona como se fosse uma "máfia". Como afirma SAMPSON (1999, p. 14), o preconceito pode ser considerado primariamente injustificado, por envolver uma generalização incorreta, tratando indivíduos em termos de membros de seu grupo, ao invés de referir-se a eles como indivíduos únicos, como realmente são.

\begin{abstract}
A categoria sociopolítica que o estrangeiro ocupa o fixa numa alteridade que implica, necessariamente, uma exclusão. [...] Até o século XIV era chamado estrangeiro, em francês, aquilo que era incompreensível ou fora do comum. Só posteriormente surgiu o substantivo que se refere a um "fora", de conotação política. No inglês do século XVI a palavra strange dizia respeito à mulher adúltera e ao não-familiar, a alguém que a família não reconhece; só no século XVIII passa a referir-se a alguém vindo de outro país, de abroad. Em alemão, a palavra fremd designa, antes de mais nada, o não-familiar. A estrangeirice aparece bem mais tarde, para se tornar no alemão moderno ausslander.
\end{abstract}

Desse modo, parece existir na grande maioria das línguas européias num momento no qual o não-familiar se transforma em conceito político, a partir do qual, no mundo moderno, surgirá o discurso racista, fruto do discurso da ciência. (KoltaI, 2000, p. 23).

A função de depositário de aspectos tidos como indesejáveis, função esta que libera "os mesmos" de qualquer mácula na sua condição de pureza, é talvez um dos mais significativos sentidos da alteridade: torna-se desejável a identificação com aqueles que compõem o grupo dos bons, dos justos, dos capazes, dos idênticos.

Dessa maneira, é possível conceber que a pertença a um determinado grupo étnico, além de pressupor a identificação com um conjunto de significações transmitidas pelos agentes sociais apropriados (considerando o processo de identificação como um processo inconsciente), pressupõe também a não-identificação com os outros, tidos como plenos de características 
indesejadas. Tornar-se idêntico é, portanto, um fenômeno que contém simultaneamente a afirmação de si e a recusa do outro. As características negativas atribuídas ao outro residem no imaginário daquele que as atribui, exercendo a função de válvula de escape para a violência interna e mesmo para angústias psicóticas, tal como a história tem demonstrado.

O falseamento da realidade, levado a efeito pelo indivíduo preconceituoso, como forma de defesa de ameaças imaginárias, utiliza, para sua justificação e fortalecimento, de estereótipos proporcionados pela cultura. Dessa forma, como no dizer de CROCHIK (1997, p. 18), o estereótipo é um produto predominantemente cultural, mas que se relaciona diretamente com mecanismos psíquicos infantis.

\section{O preconceito: sintoma social}

A questão do preconceito ${ }^{6}$ é, portanto, uma questão de cunho eminentemente afeito à Psicologia Social, na medida em que trata de um fenômeno que se manifesta como um sintoma, mas cujas formas e conteúdos pertencem à cultura. É um fenômeno intergrupal, envolvendo as formas pelas quais indivíduos de um grupo lidam com aqueles de outro grupo. Daí que tanto a Psicanálise quanto a Antropologia, a Sociologia e a Psicologia Social ocupam-se da análise, da compreensão e da busca de alternativas para lidar com as origens, as formas de manifestação, as predisposições, as relações entre o objeto vítima do preconceito e as leis do funcionamento psíquico e as possíveis profilaxias desse fenômeno.

De acordo com Jahoda; Ackerman (1969, p. 26-27), em sentido restrito,

6 "Do Latim prae, antes, judicium, julgamento, pode ser definido como crenças e valores apreendidos, que conduz um indivíduo, ou grupo de indivíduos, a ser contra membros de grupos previamente a experiências atuais com estes grupos. [...] Estas generalizações são, invariavelmente, derivadas de informações incorretas ou incompletas sobre o outro grupo. [...] Aos indivíduos do grupo vítima do preconceito é negado o direito de serem reconhecidos e tratados como indivíduos com características individuais." (CASHMORE, 1996) [tradução da autora]. "Preconceito é definido como uma injustificada, usualmente negativa atitude dirigida a outros devido sua categoria social ou sua condição de pertença a um grupo." (SAMPSON, 1999, p. 15) [tradução da autora]. 
o "preconceito" deve ser distinguido do pré-conceito e do pensar estereotipado. Representa uma subcategoria do pré-conceito, apoia-se no pensar estereotipado, sem confundir-se com um ou com outro. Do ponto de vista psicológico é [...] uma atitude de hostilidade nas relações interpessoais, dirigida contra um grupo inteiro ou contra os indivíduos pertencentes a ele, e que preenche uma função irracional definida dentro da personalidade. Daí se depreende que a verdadeira motivação do preconceito não surge das qualidades reais do grupo contra o qual se dirige. [...] Só cabe falar em preconceito no caso em que (as crenças e afirmações estereotipadas empregadas contra o outro sejam consideradas) como racionalização de uma hostilidade irracional enraizada em sua personalidade. ${ }^{7}$

Freud desenvolveu, em Psicologia das massas e análise do eu (1973a, p. 2583-2584), importante conceito, cuja tese foi lançada desde $O$ tabu da virgindade, que é o do narcisismo das pequenas diferenças, que subsidia a compreensão da hostilidade ao "diferente".

Segundo o testemunho da psicanálise, quase todo relacionamento afetivo íntimo [...] contém um fundo de sentimentos negativos e hostis, que só escapam da percepção devido ao recalque. [...] A mesma coisa acontece quando os homens se reúnem em unidades maiores. [...]

Nas aversões e repulsas que se manifestam de modo aparente em relação aos estrangeiros, podemos reconhecer a expressão de um amor de si, de um narcisismo, que aspira a se afirmar e se comporta como se a existência de uma distância em relação às formações individuais que desenvolveu acarretasse uma crítica dessas e uma necessidade de remanejá-las.

Assim, segundo KoltaI (2000, p. 95), "baseada no narcisismo, constantemente alimentada por ele e remetendo mais profundamente ao desamparo infantil, a intolerância assimila estrangeiro a hostil."

$7 \mathrm{O}$ trabalho de ambos os autores, Distúrbios emocionais e anti-semitismo, que pretendeu demonstrar que o anti-semitismo é um preconceito neste último sentido, teve sua hipótese plenamente confirmada. 
Em O mal-estar na civilização, Freud (1973b, p. 3017) trata tanto da universalidade da hostilidade dos homens uns em relação aos outros quanto da crueldade inerente ao ser humano. Aí, Freud defende a tese de que a "fraternidade está fundada sobre a segregação, o amor do semelhante no ódio do diferente; a ponto de a sociedade que se quer fundada no amor desembocar, necessariamente, em seu oposto que é a intolerância." (KoltaI, 2000, p. 39). O inimigo, o estrangeiro, passa, dessa forma, a compor o papel necessário para a consecução da unidade do grupo.

$\mathrm{Na}$ interpretação de Levinas, ao tratar do papel que a filosofia ocidental confere ao outro, terminando por reduzi-lo a um outro eu, fica evidenciado o insuportável que é admitir a diferença:

... a filosofia ocidental coincide com o desvelamento do Outro, lá onde o Outro, ao se manifestar como ser, perde sua alteridade. A filosofia está impregnada, desde sua infância, por um horror do Outro que permanece Outro, por uma insuperável alergia. (Levinas apud KolTAI, 2000, p. 61) [grifo meu].

A formação do preconceito, além de conter em si a necessidade de tornar-se distinto do outro e de servir de âncora para a violência, parece, preferencialmente, ocorrer em tenra infância em famílias com condutas disciplinares rígidas. Segundo Adorno (1994), o preconceito é uma herança da "personalidade autoritária". ${ }^{8}$ Quando criança, o sujeito com este tipo de personalidade era inseguro, dependente, medroso e inconscientemente hostil com relação aos pais. Quando adulto, possui uma grande raiva reprimida - devido a sua insegurança básica -, manifestada no deslocamento agressivo contra grupos minoritários e/ou pouco poderosos. Ao mesmo tempo, o indivíduo man-

8 De acordo com Crochik, "sem desconsiderar o peso preponderante dos fatores objetivos, relacionados às esferas política, econômica e cultural, (os estudos de ADORNo et al. (1965) e de ACKERMAN; JAHODA (1969)] entenderam que era necessário compreender os fatores subjetivos presentes no fenômeno do preconceito, pois isso poderia contribuir para minimizar a violência e a destruição presentes, através de políticas educacionais preventivas ou restauradoras enquanto a sociedade nas suas condições objetivas, isto é, políticas e econômicas, não puder ser alterada." (1997, p. 55-56). 
tém uma atitude respeitosa e obediente em relação à autoridade. Muitos têm apontado o preconceito como uma matéria de aprendizagem: as pessoas simplesmente assimilam preconceitos contra grupos de quem se identificam (pais ou pares, em geral). Daí por que se preservam de uma geração à outra.

\section{Escola, o espaço comum de reflexão sobre a ação própria: sonho ou realidade?}

Pensar nossa ação docente, de maneira sistemática e permanente, faz sentido quando contextualizada e definida a escola que queremos, isto é, a Escola que alicerce uma sociedade que nunca mais permita a barbárie: "Todo o debate sobre parâmetros educacionais é nulo e indiferente em face deste que Auschwitz não se repita."(Adorno, 1994) Para tanto, além de pensar no futuro, é preciso exorcizar feridas de um passado de escravidão ${ }^{9}$ e de um presente globalizado no qual alguns se conectam à internet enquanto outros não têm acesso à rede de esgotos (BAIBICH, 1995).

Algumas premissas acerca do aprender e do ensinar têm sido propostas, no âmbito da literatura, para que esta "Escola que não permita que Auschwitz se repita" possa ser construída. Destacamos aqui apenas algumas destas concepções. Fazemos desta forma, muito mais no intuito de sublinhar que, ainda que possamos saber o que é uma sociedade justa e que no discurso dificilmente alguém admita lutar contra isto, nossa prática não parece corresponder à estas convições e a estes anseios. Uma distância imensa entre "intenção e gesto" existe entre a escola do "dever-ser" e a escola que "é". Senão, vejamos:

a) ensinar inexiste sem aprender e vice-versa, e foi aprendendo socialmente que, historicamente, homens e mulheres descobriram que era possível ensinar;

9 Estudo de Flávia Rosemberg, da Fundação Carlos Chagas, mostra que das crianças de sete anos ou mais que ainda estão na pré-escola, 63,5\% são negras ou pardas, enquanto 36,5\% são brancas. Segundo a pesquisadora, a retenção de alunos negros e pardos também é maior no ensino fundamental. (Folha de São Paulo, 22 out. 2001). 
b) os homens são seres programados, mas para aprender. E como diz Paulo Freire, quanto mais criticamente se exerça a capacidade de aprender tanto mais se constrói e desenvolve a "curiosidade epistemológica", sem a qual não alcançamos o conhecimento cabal do objeto;

c) "a pedagogia que se constitui a partir do boicote preconceituoso à relação grupal, à palavra do aluno, à ação criativa é uma pedagogia da dependência, da subserviência. Uma pedagogia que suprime a liberdade no ponto de partida só pode colher a ignorância no ponto de chegada." (BECKER, 1993);

d) é preciso que o professor passe a pensar o seu pensamento e conhecer o seu conhecimento. $\mathrm{O}$ desvelamento da epistemologia subjacente à ação docente é caminho obrigatório para a transformação da escola hoje;

e) faz-se necessário romper com o discurso da Pedagogia que serve, em realidade, de máscara para a manutenção do status quo de uma escola que funciona como máquina de produção de sujeitos obedientes e úteis: "E nisto, tenha o regulamento que tiver, pertença a esta ou àquela entidade mantenedora, a escola é sempre igual a si mesma e se repete nas geografias diversas, nas histórias, nos níveis múltiplos que desdobra, desdobrando-se e aos seus atos e efeitos."(Beltrão, 1997, 1998)

No âmbito de nossas discussões acadêmicas, temos delimitada a generalidade da escola que pretendemos, cujo horizonte da Paz e da constituição de sujeitos autônomos, intelectual e moralmente, tem sido sobejamente ressaltado. Da mesma forma, professores e profissionais da educação em geral reconhecem alguns fenômenos que, em seu entendimento, concorrem para a multideterminação da não-efetivação desta "Escola do desejo". Algumas destas questões, entendidas como próprias do momento, são caracterizadas como fundamentais para justificar as dificuldades da escola hoje, e apareceram de maneira recorrente para justificá-la enquanto tal. Dentre elas, há as que nos pareceram de relevância especial: a que tange a alteridade e a autonomia e a que se refere ao papel da escola perante um tempo no qual a família já não cumpre mais papéis até então de sua responsabilidade.

$\mathrm{O}$ assunto das diferenças e da identidade surge como algo que se faz cada vez mais necessário desenvolver, mas que encontra significativas barreiras. A importância de permitir que o conflito passe a ter espaço, para que as diferenças se coloquem e seja possível lidar com a condição de enxergar a realidade de diversos pontos de vista, também constitui tônica deste tipo de consideração. O conflito, visto como estopim da reflexão conjunta e da reelaboração da ação, é consensual enquanto ponto de vista conceitual, entre- 
tanto, a dificuldade para que isto se configure na prática também é, via de regra, levantada.

De forma bastante geral, é possível constatarmos que no nível do discurso a escola já reconhece a importância do significado do pensar sobre si, sobre sua ação e sobre o outro, para poder transformar. A questão nevrálgica reside nos obstáculos que se impõem para que esta concepção possa se espraiar, como atitudes, para os reais espaços de ação docente dos profissionais envolvidos na arte de ensinar.

\section{Da distância entre intenção e gesto}

Com o intuito de ilustrar as reflexões acerca do processo de "varredura para debaixo do tapete", ou técnica Fred Flintstone, ${ }^{10}$ utilizado na maioria dos espaços de socialização em nossa sociedade e, não menos notadamente, nas escolas, busquei, mediante entrevista com alguns professores de uma escola pública do estado do Paraná, dados para melhor diagnosticar a atitude da escola, bem como a dos professores, no que tange ao reconhecimento da existência do preconceito, à sua profilaxia e/ou à sua profilexia. ${ }^{11}$

A escola em questão foi escolhida para as entrevistas precisamente por suas características diferenciadas na rede estadual como um todo, de maior envolvimento político com uma proposta de sociedade mais igualitária no que se refere a direitos e deveres de cidadania.

Logo no primeiro contato com esta instituição de ensino percebemos claramente o "clima politizado" que contagia todos, desde os funcionários da cozinha até os orientadores pedagógicos. Espalhados pelas paredes, cartazes com dizeres de artistas e escritores que se destacaram pelos questionamentos em suas obras acerca da desigualdade social no mundo. Na sala dos professo-

10 Protagonista do desenho animado intitulado Os Flintstones do estúdio Hanna Barbera, que ao ser instado por sua mulher, Wilma, a varrer a casa, costuma esconder a sujeira sob o tapete.

11 Os dados foram colhidos com o apoio dos alunos Andreia Moessa, Hermelina Maria Sandman, Ionara R. Carraro Bonança, Luis Fernando Dietzel Ferraro, Mariana Cardieri Mendonça e Maria Augusta de Mendonça Guimarães, da disciplina de Prática de Ensino de Psicologia da UFPR, a quem agradeço a valiosa cooperação. 
res, alguns dos jornais mais importantes do país, como Folha de São Pau$l o$, estão à disposição todos os dias para leitura. Dentro dessa sala, discussões fervorosas sobre temas da atualidade ou questões políticas. Grande parte dos professores pertencem a partidos políticos. Recortes de jornais e revistas criticando o atual governo do Estado podem ser vistos nas paredes da sala.

O pensar sobre o que está se fazendo parece muito presente no discurso da instituição. O projeto político-pedagógico refere-se à construção de uma identidade própria baseada na autonomia. A escola percebe-se tendo construído sua identidade baseada na autonomia; autonomia de decidir continuar com o curso de Magistério (abolido por força de decisão da Secretaria de Educação), de juntar todos os funcionários da escola para montar um grupo de discussão com a tarefa de realizar um sólido regimento escolar e até mesmo de criticar abertamente a Secretaria de Educação pelo fato de ter cortado verbas para a manutenção de certas atividades. Essa identidade é reconhecida pelas outras escolas do estado e na comunidade. ${ }^{12}$

Para a escola, os fundamentos filosóficos que devem nortear a proposta pedagógica possuem extremo valor e devem, portanto, "ter significação própria e singular da unidade escolar", que deve estar sempre em constante reflexão. Assim, como decorrência, são estabelecidos como princípios a autonomia, a identidade e a diversidade, envolvendo a construção da cidadania e inclusão social através de desenvolvimento do pensar sobre estes problemas e de atividades a serem trabalhadas além das propostas em currículo normal.

O projeto político pedagógico da referida escola destaca-se por produzir, através de sua formulação, um diferencial dentre as perspectivas de ensino. Foi estruturado de maneira a abarcar, ao máximo possível, as questões que permeiam o ensino no Brasil. O projeto deixa claro que desenvolve o conteúdo da disciplina para a educação geral com o objetivo de "compreender a existência humana, a partir de concepções presentes nos fundamentos filosóficos e princípios norteadores de diretrizes: subjetividade, singularidade, diversidade e afetividade. Apresenta-se, para propor alternativas teóricas que favoreçam ao aluno, o entendimento acerca da construção de sua identidade, da característica peculiar do movimento de vida que atravessa, e das relações que estabelece.

12 Essa afirmação está baseada em depoimentos informais que tive a oportunidade de ouvir vindos de outros professores de escolas públicas e até mesmo da professora de Psicologia, que disse ter escolhido aquela escola para dar aula por que já sabia desta identidade. Num destes depoimentos, a professora comenta em tom pejorativo as características "esquerdistas" da escola, apresentando os professores e funcionários como se fossem "encrenqueiros". 


\section{Uma leitura de dados}

Mediante questionário de entrevista, com questões de caráter aberto e fechado, realizada com nove professores do corpo da escola e um da direção, buscamos perscrutar a análise dos mesmos com respeito à existência do preconceito, bem como com relação a política da escola no que se refere a este delicado tema. Da interpretação do discurso dos professores algumas questões, em especial, merecem destaque para os propósitos deste artigo.

O primeiro aspecto que merece tratamento diferenciado é o relativo ao reconhecimento da existência do preconceito. Este reconhecimento ocorre facilmente quando o espaço referido é de caráter mais distante do que o do espaço próprio do sujeito que fala, isto é, no "fora", ou quando o sujeito "dito preconceituoso" é outro que não o próprio sujeito da fala. Não parece haver crítica da parte do respondente, no sentido de avaliar que o espaço menor é contido em espaços maiores, ou seja, não tem a condição de ilha.

Assim, todos os professores reconhecem a existência do preconceito no Brasil e "em grande escala", classificando-o, mais comumente, como de cor, raça, gênero, opção sexual, inteligência, classe social. Quando a questão busca saber o que ocorre na cidade de Curitiba, as respostas, também unânimes, são explicadas por argumentos tais como: "cidade muito conservadora", "muitos imigrantes", "chega a ser natural numa cidade assim", "tem preconceito contra tudo, mas o pior é racial".

Paradoxalmente, se não levarmos em conta este fenômeno do "distante possível", quando se trata de reconhecer a existência na escola aparecem as seguintes considerações: "não percebo ainda que no geral exista", "não, mas deve ter em relação a mulher", "não existe". Dentre os sete professores que lhe reconhecem a existência, as referências são com relação a "alunos pobres e sujos", "menina negra", "menina manca", "meninas grávidas", "classe social", "menina com problema emocional", "político, contra o professor que não é de esquerda", "político, contra o professor que é de esquerda". Interessante referir que uma professora, ao final da entrevista, "lembra" que houve um caso de racismo da então direção da escola contra um professor negro, que acabou na justiça, com ganho de causa para o professor.

Portanto, parece ser possível, nessa lógica (que em realidade é uma lógica de negação ou "Fred Flintstone"), que uma escola em Curitiba, no Brasil, pudesse ter esta condição de oásis. Da mesma forma, no que tange à observação do preconceito em si elou nos outros, o segundo aspecto pesquisado fica viabilizado: "tem gente que pensa assim", "já ouvi no corredor", "aqui no 
Brasil ninguém tem consciência", "alguns pensam mas não dizem, porque aqui na escola não há espaço para isto", "todo mundo tem”, "já presenciei”, "há os que não assumem e os que não tem consciência", "quando aparece um caso a pessoa mostra quem é". O primeiro aspecto, porém, o do reconhecimento de sentimentos ou pensamentos preconceituosos próprios só acontece com dois professores que dizem: "todo mundo tem porque quando diz que não é, é mentiroso"; "embora tenha apresentado uma postura crítica com relação ao preconceito, não posso afirmar que não tenho nenhum."

Nosso entendimento, que corrobora nossas suspeitas, é de que tanto o dito quanto o não-dito dos discursos reconhece a existência do preconceito na escola, ainda que denuncie (na maioria das vezes, sem pretendê-lo) a não assunção do mesmo, isto é, confirma-se a existência do tabu do politicamente incorreto. Se fora e no outro, então existe. Assim, tanto do ponto de vista cultural quanto do emocional há um conforto sentido como necessário. Atitude de defesa que, socialmente falando, funciona como insidioso ataque, na medida em que, não havendo a admissão do fenômeno, também não se constroem formas de combate e/ou profilaxia.

O próprio representante da direção, cujas concepções teóricas e políticas parecem bastante consistentes, expressa, sem intencionalidade, uma contradição no discurso. Apesar do reconhecimento veemente do preconceito no Brasil e em Curitiba, quando se refere à escola, trata apenas de questões muito mais ligadas à epistemologia subjacente às ações docentes do que propriamente de manifestações dos preconceitos que refere ao tratar do país e da cidade, quais sejam, racial, social, religioso, de costumes (cultural) e político: "um preconceito muito grande aqui na escola é do professor em relação ao aluno: pensam que o aluno é depositário do conhecimento do professor. Assim o aluno é o foco dos problemas de aprendizagem e disciplina. [...] Existe $15 \%$ dos professores com esta disciplina preconceituosa."

Um outro aspecto que merece foco de análise é o que se refere ao tratamento dispensado pela escola à questão do preconceito e de suas conseqüências. Aqui, o que se manifesta é uma afirmação de um fenômeno bastante comum na Escola, que é o fenômeno do "esconderijo conceitual" (BAIBICH, 1995).

No que tange a um tema tão nevrálgico quanto este não poderia ser diferente. Assim, ainda que exista uma certa percepção dos professores quanto às intenções da direção, tanto do ponto de vista de programa de ensino, quanto do de espaço de tempo, ou do tratamento dispensado às vítimas e a seus pais, buscar atacar o problema, por parte da maioria, é uma idéia que não toca no cerne da questão. Com exceção de três professores: um deles 
acha que a escola não trabalha com o tema e dois, ao contrário, que trabalha intensamente (sendo que um deles, representante da direção, afirma: "Considero a ação intensa e que apresenta resultados de ordem prática"), os outros seis, de formas variadas, consideram apenas razoável o que se faz, entendendo que a forma não direta acaba sendo também pouco efetiva. Uma das falas exprime exemplarmente as outras: “...Faz-se também atividades em sala, mas sem falar abertamente que é uma atividade para trabalhar o preconceito. A gente acaba trabalhando isso inconscientemente com a turma, sem que eles saibam que estamos falando disso."[grifo meu] ${ }^{13}$

É importante notarmos que mesmo existindo uma clara noção de que a escola tem a intenção (daí que optou inclusive pelas disciplinas de Psicologia, Sociologia e Filosofia) de trabalhar a questão do preconceito, bem como de que toma sempre uma atitude pró-ativa no sentido de defesa das vítimas, há também a concepção de que o que ocorre é mais no sentido de apaziguamento do conflito do que de modificação.

É o representante da direção da escola quem se manifesta:

Esta escola foi montada com estas idéias de pluralidade, que inclusive fazem parte das questões legais. A constituição e o estatuto da criança e do adolescente são base do projeto político pedagógico da escola. Mas isso não isenta as manifestações de preconceito, porque já estão cristalizados no imaginário do professor e do aluno.

Entretanto, quando a pergunta se refere à forma pela qual a escola deveria tratar o problema, apenas dois são enfáticos em dizer "diretamente, sem acobertar" os outros sete sugerem ou ignorar, pois "quando fala aparece", ou utilizar as vias da informação (cinco entrevistados) ou, da mera "convivência". Isto denota que embora se faça possível diagnosticar a distância entre o que se pretende e o que se faz, bem como suas conseqüências, quando se trata de imaginar o combate a este fenômeno a idéia de "colocar o dedo na ferida" assusta. O representante da direção, cuja concepção é a de que a escola

13 Cabe notar aqui, a epistemologia subjacente à ação docente, que considera que o conhecimento vindo de fora inscreve-se, sutilmente, na tábula rasa. Mais do que isto, considerase que o tabu deve permanecer um tabu, escondido. Isto apenas reforça o que se pretende esconder. 
"deve tratar o problema a partir de uma proposta que considere a questão do preconceito, trabalhar junto aos professores, pais, conceitos de democratização e pluralidade a fim de superar o grau (de preconceito) existente", assume, sem crítica ou mesmo consciência, que a atitude da escola, corroborando a "distância entre intenção e gesto" é, desde que viável, a de varrer para baixo do tapete: "quando o problema é menor não faz um escândalo, mas quando é grande é discutido."

Um último aspecto a ser comentado diz respeito a unânime percepção quanto as conseqüências para a vítima do preconceito: "auto-exclusão", "inibição", "dificuldades de aprendizagem", "troca de sala", "troca de escola" e "raros reagem". A vítima, portanto, parece carregar também, o estigma da culpa que lhe é imputada, como se realmente a possuísse.

\section{De Fred à Wilma Flintstone: algumas considerações}

Ainda que estas análises sejam preliminares, dado que o material permitirá o aprofundamento das mesmas, de qualquer forma, se faz possível afirmar que a educação parece muito distante de evitar que Auschwitz se repita. A escola, mesmo a que se pretende voltada à convivência entre os diferentes, enfrenta, além dos inimigos já conhecidos, a grande e aparentemente intransponível barreira da negação que, deliberadamente ou não, promove a manutenção do estado de preconceito bem como da geração de indivíduos preconceituosos.

Para além das políticas de programas e apaziguamentos, sugerimos políticas agressivamente positivas, que olhando o problema nos olhos trate de evitá-lo e combatê-lo. Essa transformação passa, também, necessariamente, pela escola.

Como Wilma Flintstone, é preciso levantar o tapete. 


\section{REFERÊNCIAS}

ADORNO, T. W. Educação após Auschwitz. In: COHN, G. (Org.). Theodor W. Adorno. São Paulo: Ática, 1994.

BAIBICH, T. M. Perfil da extensão das universidades públicas brasileiras. Cadernos de Extensão da Pró-Reitoria de Extensão da UFPR Curitiba, Ano 1, n.1, 1995.

BAIBICH, T. M. Fronteiras da identidade: o auto-ódio tropical. Curitiba: Moinho do Verbo, 2001.

BECKER, F. A epistemologia do professor: o cotidiano da escola. Petrópolis: Vozes, 1993.

BELTRÃO, I. C. Pedagogia e escola: o discurso sobre a educação e a máquina de disciplinar. Pátio-revista pedagógica, Porto Alegre, Ano 1, n. 3, p. 30-32, nov./jan., 1997/1998.

CASHMORE, E. Dictionary of race and ethnic relations. London: Routledge, 1996.

CROCHIK, J. L. Preconceito: indivíduo e cultura. São Paulo: Robe, 1997.

FREIRE, P. Pedagogia da autonomia: saberes necessários à prática educativa. São Paulo: Paz e Terra, 1996.

FREUD, S. Psicologia de las masas y analisis del "yo”. Madrid: Biblioteca Nueva, 1973a.

FREUD, S. El malestar en la cultura. Madrid: Biblioteca Nueva, 1973b.

FREUD, S. El tabú de la virginidad. Madrid: Biblioteca Nueva, 1973c.

INDICADORES sociais da década de 90. Folha de São Paulo, 5 abr. 2001.

JAHODA, M.; ACKERMAN, N. W. Psicoanálisis del antisemitismo. Buenos Aires: Paidós, 1962.

KOLTAI, C. A segregação, uma questão para o analista. In: KOLTAI, C. (Org.). $O$ estrangeiro. São Paulo: Escuta, 1998.

KOLTAI, C. Política e psicanálise: o estrangeiro. São Paulo: Escuta, 2000.

ROSEMBERG, F. Preconceito sutil tira negros da universidade. Folha de São Paulo, 22 out. 2001.

SAMPSON, E. E. Dealing with differences: an introduction to the social psychology of prejudice. Orlando: Harcourt Brace \& Company, 1999. 
VIÑAR, M. O reconhecimento do próximo. Notas para pensar o ódio ao estrangeiro. In: KOLTAI, C. (Org.). O estrangeiro. São Paulo: Escuta, 1998.

Texto recebido em 10 fev. 2002 Texto aprovado em 22 abr. 2002 